\title{
Protective effects of bacteriophage on experimental Lactococcus garvieae infection in yellowtail
}

\author{
T. Nakai ${ }^{1, *}$, R. Sugimoto ${ }^{1}$, K.-H. Park ${ }^{1}$, S. Matsuoka ${ }^{2}$, K. Mori ${ }^{3}$, T. Nishioka ${ }^{4}$, K. Maruyama ${ }^{4}$ \\ ${ }^{1}$ Faculty of Applied Biological Science, Hiroshima University, Higashihiroshima 739-8528, Japan \\ ${ }^{2}$ Ehime Prefectural Fish Disease Control Center, Uwajima 798-0087, Japan \\ ${ }^{3}$ Kamiura Station, Japan Sea-Farming Association, Kamiura, Oita 879-2602, Japan \\ ${ }^{4}$ Goto Station of Japan Sea-Farming Association, Nagasaki 853-0510, Japan
}

\begin{abstract}
The present study describes the in vitro and in vivo survival of Lactococcus garvieae bacteriophages and the potential of the phage for controlling experimental $L$. garvieae infection in yellowtail. Anti-L. garvieae phages persisted well in various physicochemical (water temperature, salinity, $\mathrm{pH}$ ) and biological (feed, serum and alimentary tract extracts of yellowtail) conditions, except for low acidity. In the in vivo, the phage PLgY-16 was detected in the spleens of yellowtail until $24 \mathrm{~h}$ after intraperitoneal (i.p.) injection, or the phage was recovered from the intestine of yellowtail $3 \mathrm{~h}$ after the oral administration of phage-impregnated feed but undetectable $10 \mathrm{~h}$ later. Simultaneous administration of live $L$. garvieae and phage enhanced recovery of the phage from the spleen or intestine. The survival rate was much higher in yellowtail that received i.p. injection of the phage after i.p. challenge with $L$. garvieae, compared with that of control fish without phage injection. When fish were i.p.injected with phage at different hours after L. garvieae challenge, higher protective effects were demonstrated in fish that received phage treatment at the earlier time. Protection was also obtained in yellowtail receiving phage-impregnated feed, in which fish were challenged by an anal intubation with $L$. garvieae. Anal-intubated L. garvieae were detected constantly in the spleens of the control fish, while they were detected sporadically and disappeared from the phage-treated fish $48 \mathrm{~h}$ later. On the other hand, orally administered phage was detected at high plaque-forming units from the intestines and spleens of the phage-treated fish until $48 \mathrm{~h}$ later. These results indicate that intraperitoneally or orally administered anti- $L$. garvieae phage prevented fish from experimental $L$. garvieae infection, suggesting potential use of the phage for controlling the disease.
\end{abstract}

KEY WORDS: Bacteriophage - Lactococcus garvieae - Enterococcus seriolicida Yellowtail - Seriola quinqueradiata. Phage-therapy - Biological control

\section{INTRODUCTION}

The disease caused by Enterococcus seriolicida (Kusuda et al. 1991) has been responsible for serious economical damage to yellowtail Seriola quinqueradiata aquaculture in Japan since its first occurrence in 1974, mainly due to frequent occurrence of the disease in marketable-sized fish (Kitao 1993, Muroga 1997). Recent studies on the taxonomic position of E. seriolicida revealed that this is a junior synonym of Lactococcus garvieae (Eldar et al. 1996, Teixeira et al. 1996). As L. garvieae is ubiquitous in fish and their culture environments (Kitao et al. 1979), it is believed that the bacterium is a typical opportunistic pathogen, and there-

·E-mail: nakaitt@ipc.hiroshima-u.ac.jp fore reducing stress factors, such as poor water quality, overcrowding, overfeeding and insufficient nutrition, is generally important in controlling the disease (Plumb 1994). However, yellowtail culture in Japan depends on chemotherapeutics, and frequent chemotherapy has allowed drug-resistant strains of $L$. garvieae to develop (Aoki et al. 1990). Experimental vaccinations against $L$. garvieae infection have been reported (Iida et al. 1982, Kusuda et al. 1996), and recently a commercial vaccine against lactococcal infection of yellowtail was developed. The evaluation of this vaccine by fish farmers is now in progress.

Previously, we found a virulent bacteriophage, designated as PLgY, specific to Lactococcus garvieae isolated from diseased fish, and the phage was identified as a member of the family Siphoviridae (Park et al. 
1997). L. garvieae strains from diseased fish were divided into 14 or more phage types by using several phage strains isolated from fish and culture environments, with a major phage type A (Park et al. 1998).

Bacteriophages can theoretically be a tool for treating infectious disease, but there have been a limited number of reports on their potential use as biological control agents for naturally occurring diseases. Phages of some fish pathogenic bacteria, such as Aeromonas salmonicida (Paterson et al. 1969, Rodgers et al. 1981), A. hydrophila (Merino et al. 1990), and Yersinia ruckeri (Stevenson \& Airdrie 1984), have been reported but no attempts at phage control were made for bacterial infections in fish. Although 2 papers, Wu et al. (1981) and Wu \& Chao (1982), mentioned the applicability of phages for biological control of fish pathogens ( $A$. hydrophila and Edwardsiella tarda), at present we have no reliable reference experiments for phage therapy or control in the field of fish pathology. On the other hand, a series of investigations by Smith and colleagues, in which phages were successfully used to treat a generalized and a cerebral Escherichia coli infection in mice (Smith \& Huggins 1982) or $E$. coli diarrhoea in calves, lambs and piglets (Smith \& Huggins 1983, Smith et al. 1987a, b), and a recent publication by Barrow et al. (1998) on potential use to prevent E. coli infection in chickens, prompted the present work. The renewed interest in the potential of phage therapy and prophylaxis was assessed by Barrow \& Soothill (1997).

In this paper, we describe the survival of Lactococcus garvieae phages under various in vitro conditions, the in vivo fate of the phage in yellowtail after intraperitoneal injection of phage or oral administration of phage-impregnated feed, and the protective effects of intraperitoneally or orally administered phage with respect to experimental $L$. garvieae infection in yellowtail

\section{MATERIALS AND METHODS}

Bacteria and phage. Lactococcus garvieae strain No. 16. which was isolated from a diseased yellowtail, was used in all the experiments. This strain belongs to the $\mathrm{KG}$ phenotype, encapsulated virulent type (Kitao 1982, Yoshida et al. 1997) and to phage type $A$, the major phage type of $L$. garvieae isolated from yellowtail (Park et al. 1998). Prior to the onset of experiments, bacteria were subcultured on Trypto-soy Agar (TSA, Eiken Co. Ltd) at $25^{\circ} \mathrm{C}$ for $48 \mathrm{~h}$. Colony-forming units (CFU) were enumerated by a standard spread plate technique using TSA. Three phages having different infectivities, designated as PLgY-16, PLgY-30 and PLgW-1, were used here. The PLgY-16 and PLgY-30 were obtained from $L$. garvieae cultures isolated from diseased yellowtail, and the PLgW-1 was isolated from natural seawater in the previous studies (Park et al. $1997,1998)$. These phages were propagated in L. garvieae strain No. 16 using a double-layer agar method (Paterson et al. 1969). Briefly, a mixture of phage and bacteria was cultured in soft agar overlaid TSA at $25^{\circ} \mathrm{C}$ for $24 \mathrm{~h}$. After centrifugation of the soft agar showing plaques, $10^{2}$ to $10^{3}$ plaque-forming units (PFU) plate ${ }^{-1}$, the supernatant was filtered through a $0.45 \mu \mathrm{m}$ membrane filter and the phage concentration was adjusted

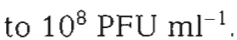

Fish. Juvenile (average 5 to $9 \mathrm{~g}$ ) and young (average 30 to $50 \mathrm{~g}$ ) yellowtail, which were reared at the Ehime Prefectural Fish Disease Control Center and at Japan Sea-Farming Association (Kamiura Station and Goto Station), were used in this study. Fish were acclimated to laboratory conditions for more than $3 \mathrm{~d}$ in 40 or $500 \mathrm{l}$ tanks with flow-through system and were not fed for $2 \mathrm{~d}$ before the commencement of each experiment. The tank water temperature was $23^{\circ} \mathrm{C} \pm 2^{\circ} \mathrm{C}$ throughout the experimental period.

In vitro survival of phages. Phages were inoculated in the test media to $10^{4}$ to $10^{5} \mathrm{PFU} \mathrm{m} \mathrm{m}^{-1}\left(\mathrm{~g}^{-1}\right)$ and incubated with gentle agitation. At scheduled incubation intervals, $0.1 \mathrm{ml}(0.1 \mathrm{~g})$ of test media was used for phage PFU assays using the double-layer agar method. All experiments were performed at $25^{\circ} \mathrm{C}$, except for those testing the effect of temperature. The test media were water (distilled water, natural seawater, doublestrength artificial seawater), fish feed (moist pellet), yellowtail serum, and extracts of alimentary tracts (stomach, pyloric caecum and intestine) of yellowtail. The effects of $\mathrm{pH}$ were examined by incubating phage for $30 \mathrm{~min}$ in a $0.2 \mathrm{M}$ borate- $0.05 \mathrm{M}$ citrate- $0.1 \mathrm{M}$ phosphate buffer at different pHs $(2.5,3.0,3.5,4.0,7.0,9.0$, and 11.0 ). The serum was collected from 5 young yellowtail (average $40 \mathrm{~g}$ ) and filtered through a $0.45 \mu \mathrm{m}$ membrane filter. The stomach, pyloric caecum and intestine were prepared from an adult yellowtail weighing $2.5 \mathrm{~kg}$. One gram of these organs was homogenized with $9 \mathrm{ml}$ of the borate-citrate-phosphate buffer at different $\mathrm{pHs}(3.5,7.4$ and 10.0$)$, centrifuged at $12000 \times g$ for $30 \mathrm{~min}$, and the supernatant was filter $(0.45 \mu \mathrm{m})$-sterilized.

In vivo survival of phage. A group of fish, average $50 \mathrm{~g}$, were injected intraperitoneally (i.p.) with the phage PLgY-16 at $10^{75}$ PFU fish ${ }^{-1}$. Another group received i.p. injection of Lactococcus garvieae live cells with a dose of $10^{8.7} \mathrm{CFU}$ fish $^{-1}$ immediately after the phage injection. Three fish were sacrificed at 3 , $12 \mathrm{~h}, 1,2,3,4$ and $5 \mathrm{~d}$ after injection. Their spleens were weighed and homogenized with sterile saline and numbers of the inoculated phage were determined by the double-layer agar method. 
A group of 20 fish (average $40 \mathrm{~g}$ ) were fed once with commercial dry pellets, which were impregnated with the phage PLgY-16, at a feeding rate of $2 \%$ fish body weight. Supplementation of phage to dry pellets was carried out by pouring uniformly $8 \mathrm{ml}$ of the phage suspension on $20 \mathrm{~g}$ of dry pellets, giving a concentration of $10^{7.4}$ PFU $g^{-1}$ of pellet. To another 20 fish, dry pellets impregnated simultaneously with PLgY-16 at $10^{7.4} \mathrm{PFU}$ $\mathrm{g}^{-1}$ and live cells of Lactococcus garvieae strain No. 16 at $10^{8.8} \mathrm{CFU} \mathrm{g}^{-1}$ were given. After $1,3,10,24$, and $48 \mathrm{~h}$ of feeding ( $30 \mathrm{~min}$ ), 3 fish were sacrificed for enumeration of phage number. The stomach and intestine were weighed and homogenized with 5 volumes of sterile saline. After centrifugation at $7000 \times \mathrm{g}$ for $3 \mathrm{~min}\left(4^{\circ} \mathrm{C}\right)$. the supernatant was serially 10 -fold diluted and then subjected to PFU assay using the double-layer agar method. In a separate experiment, fish received the phage-impregnated feed successively 3 times (once a day) and the phage number in the stomach and intestine was examined 10,24 , and $48 \mathrm{~h}$ after the final administration, as described above.

Phage treatment of fish experimentally infected with Lactococcus garvieae. Twenty yellowtail, average $50 \mathrm{~g}$, were i.p.-injected with $L$. garvieae strain No. 16 at a dose of $10^{8.7} \mathrm{CFU}_{\text {fish }}{ }^{-1}$. Phage PLgY-16 was i.p.-administered to fish at a dose of $10^{7.5} \mathrm{PFU} \mathrm{fish}^{-1}, 1 \mathrm{~h}$ after bacterial injection. Control fish $(\mathrm{N}=20)$ received Trypto-soy Broth (TSB, Eiken Co. Ltd) instead of phage suspension (Expt 1). In a second experiment, fish averaging $30 \mathrm{~g}(\mathrm{~N}=20)$ were i.p.-injected with L. garvieae at a dose of $10^{8.8} \mathrm{CFU}_{\text {fish }}{ }^{-1}$ and the phage was i.p.administered to fish at a dose of $10^{7.2} \mathrm{PFU} \mathrm{fish}^{-1}, 0,1$, and $24 \mathrm{~h}$ after bacterial injection. Another fish group (average $30 \mathrm{~g}, \mathrm{~N}=20$ ) was i.p.-injected as above but with the previously phage-infected $L$. garvieae bacteria, as a source of phage, 1 and $24 \mathrm{~h}$ after bacterial challenge. Phage infection of bacteria was performed by incubating bacteria with phage for $10 \mathrm{~min}$. Control fish $(\mathrm{N}=20)$ received only bacteria (Expt 2$)$. After bacterial challenge, mortalities of fish were recorded daily for $10 \mathrm{~d}$. The spleens of dead fish were subjected to bacterial isolation using TSA to confirm that the death was due to the lactococcal infection, with the aid of rabbit anti- L. garvieae serum.

Three groups, consisting of 20 yellowtail of average $5 \mathrm{~g}$, were used for non-parenteral administration of bacteria and phage. Twenty fish were fed with PLgY16 phage-impregnated commercial dry pellets at a concentration of $10^{79} \mathrm{PFU} \mathrm{g}^{-1}$. In a second group, 20 fish were fed with both PLgY-16 phage $\left(10^{7.9} \mathrm{PFU} \mathrm{g}^{-1}\right)$ and Lactococcus garvieae strain No. $16\left(10^{8.8} \mathrm{CFU} \mathrm{g}^{-1}\right)$ impregnated dry pellets. The third group of 20 fish received feed without phage or bacteria and served as a control group. These fish were fed once at the feeding rate of $2 \%$ body weight. After feeding for 30 min, fish were challenged with live cells of L. garvieae strain No. 16 by anal intubation of $0.1 \mathrm{ml}\left(10^{9.5} \mathrm{CFU}\right.$ $\mathrm{ml}^{-1}$ ) of bacterial suspension into the intestine. Fish were observed for $72 \mathrm{~h}$ and the spleens of dead fish were subjected to bacterial isolation described above (Expt 3). In a separate experiment using yellowtail of average $9 \mathrm{~g}, 2$ groups of 20 fish received orally phageimpregnated feed or phage-free feed in the same manner described above, and immediately after feeding were challenged with live $L$. garvieae by anal intubation. Groups of 3 fish were sacrificed to detect the inoculated phage and bacteria from their spleens and/or intestines, 3, 10, 20, 48 and $72 \mathrm{~h}$ after bacterial challenge. The organs were homogenized with 5 volumes of saline, centrifuged at $7000 \times g$ for $3 \mathrm{~min}\left(4^{\circ} \mathrm{C}\right)$ for phage enumeration, and then processed for CFU and PFU assays by the spread plate method using TSA and the double-layer agar method, respectively (Expt 4).

\section{RESULTS}

\section{Survival of phages in in vitro conditions}

In the autoclaved seawater at all tested incubation temperatures from 5 to $37^{\circ} \mathrm{C}$, PLgY-16 phage decreased gradually in the PFU but survived at $10^{3}$ to $10^{4}$ PFU $\mathrm{ml}^{-1}$ (initial concentration: $10^{4}$ to $10^{5} \mathrm{PFU} \mathrm{m} \mathrm{m}^{-1}$ ) even after $8 \mathrm{wk}$. The following experiments were carried out at an incubation temperature of $25^{\circ} \mathrm{C}$. All 3 phages (PLgY-16, PLgY-30, PLgW-1) persisted in unsterilized natural seawater for $3 \mathrm{~d}$ but perished within a week. In sterile conditions, they survived for 8 wk or longer in natural seawater, distilled water, and doublestrength artificial seawater (Fig. 1). Phage infectivities were not lost for at least $3 \mathrm{~h}$ in the moist pellets or the serum of yellowtail. A pH higher than 3.5 did not affect the infectivity of phage, while a sudden decrease in the numbers of infectious phages was observed after a 30 min exposure to $\mathrm{pH} 3.0$ and 2.5 (Fig. 2). Fig. 3 shows the survival of phages in the extracts of yellowtail alimentary tracts which were adjusted to $\mathrm{pH} 3.5,7.4$, or 10.0. Compared to the control without organ extracts, the PFUs of phages further decreased in the organ extracts at pH 3.5, particularly in the pyloric caecum, with the exception of PLgY-30 in the intestine extract. In contrast, phages were resistant to these organ extracts at $\mathrm{pH} 7.4$ and 10.0 .

\section{Fate of phage in yellowtail}

The phage appeared in the spleens at $10^{3.9} \mathrm{PFU}^{-1}$ $3 \mathrm{~h}$ after i.p. injection, and then decreased in number, reaching an undetectable level (lower than $10^{1} \mathrm{PFU}$ 

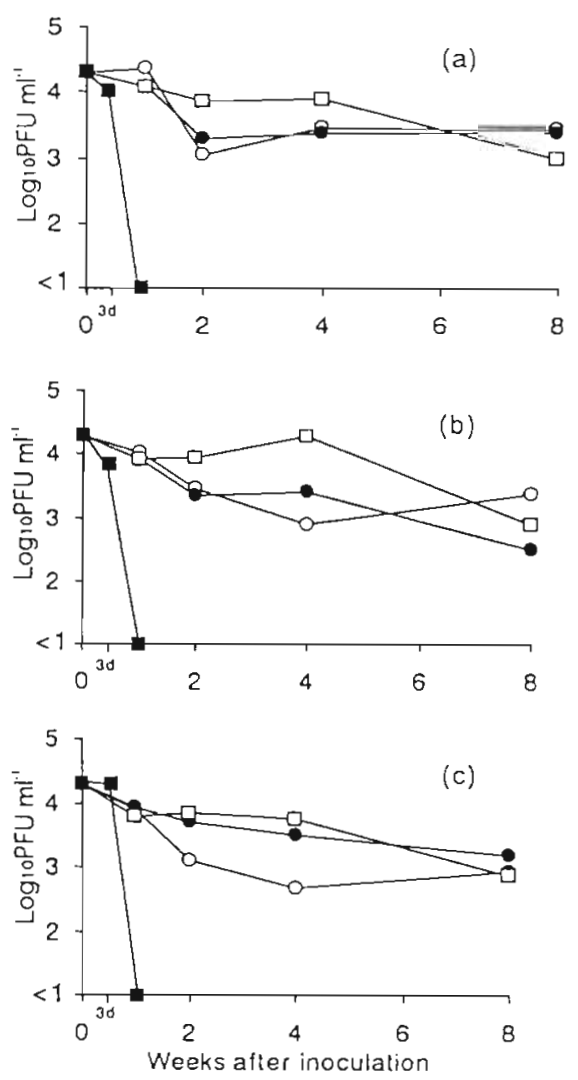

Fig. 1. Survival of Lactococcus garvieae phage strains in test waters. Phages: (a) PLgY-16, (b) PLgY-30, (c) PLgW-1; (a) unsterilized seawater, $(\bullet)$ autoclaved seawater, $(O)$ autoclaved distilled water, ( $\square$ ) autoclaved artificial seawater (doublestrength)

$\mathrm{g}^{-1}$ ) at $2 \mathrm{~d}$ post-injection. In contrast, the phage were recovered at $10^{2.2} \mathrm{PFU} \mathrm{g}^{-1}$ from fish injected simultaneously with live Lactococcus garvieae even 5 d after injection, though the number of phage decreased constantly (Fig. 4).

Fish were naturally fed dry pellets impregnated with the PLgY-16 phage alone or with both phage and live Lactococcus garvieae. One hour after feeding, the stomachs of fish were filled with undigested pellets and a small quantity of macerated pellets were ob-

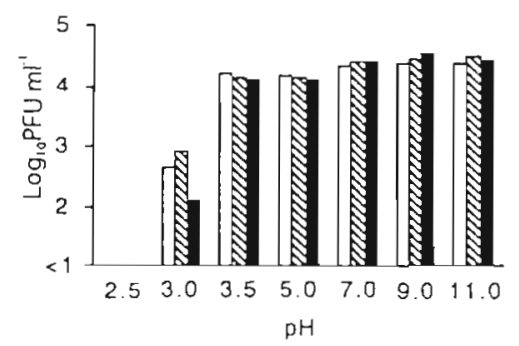

Fig. 2. Effects of $\mathrm{pH}$ on the survival of Lactococcus garvieae

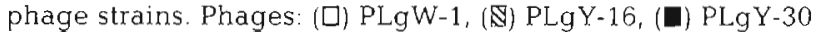
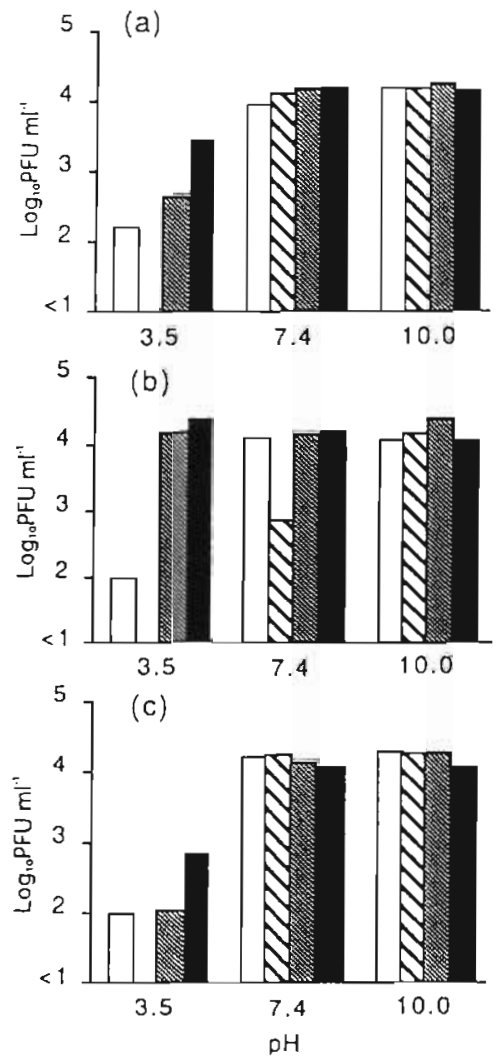

Fig. 3. Survival of Lactococcus garvieae phage strains in the extracts of alimentary tracts of yellowtail under different $\mathrm{pHs}$. Phages: (a) PLgY-16, (b) PLgY-30, (c) PLgW-1; (a) stomach, (I) pyloric caecum, intestine, (a) control without organ extracts

served in the intestine. Whole or macerated pellets were retained in the stomach even 3 or $10 \mathrm{~h}$ after feeding but had disappeared after $24 \mathrm{~h}$. Pasty contents were observed in the whole intestine 3 and $10 \mathrm{~h}$ after feeding. All intestines were vacant after $48 \mathrm{~h}$. The results of phage detection from fish receiving phageimpregnated feed are shown in Table 1. When fish

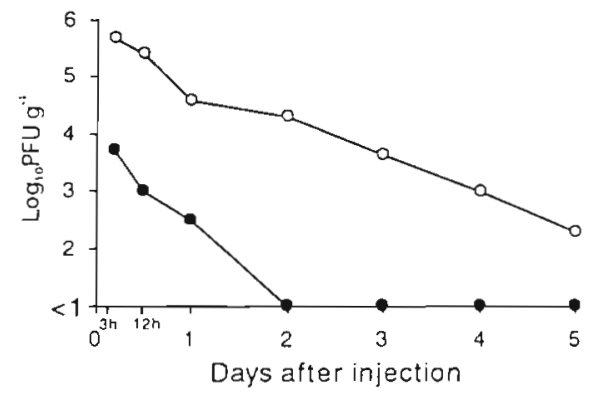

Fig. 4. Seriola quinqueradiata. Fates of the phage PLgY-16 in the spleen of yellowtail injected intraperitoneally with phage alone (1) or both phage and Lactococcus garrieae (0). Injected doses of phage and bacteria were $10^{75} \mathrm{PFU} \mathrm{fish}^{-1}$ and $10^{8.7} \mathrm{CFU}$ fish $^{-1}$, respectively. Data points represent the mean value of 3 fish at each sampling time 
Table 1 Seriola quinqueradiata. Detection of the phage PLgY-16 in the alimentary tracts of yellowtail. Fish (average $40 \mathrm{~g})$ were fed with phage-impregnated feed or both phageand Lactococcus garvieae-impregnated feed $\left(10^{7.4} \mathrm{PFU} \mathrm{g}^{-1}\right.$, $10^{8.8} \mathrm{PFU} \mathrm{g}^{-1}$ ) at a feeding rate of $2 \%$ body weight

\begin{tabular}{|c|c|c|c|c|c|c|c|}
\hline \multirow{3}{*}{$\begin{array}{l}\text { Adminis- } \\
\text { tration of }\end{array}$} & \multirow{3}{*}{$\begin{array}{l}\text { Time } \\
\text { (h) }\end{array}$} & \multicolumn{6}{|c|}{ Phage number $\left(\log _{10} \mathrm{PFU} \mathrm{g}{ }^{-1}\right)$ in } \\
\hline & & \multicolumn{3}{|c|}{ Stomach (fish no.) } & \multicolumn{3}{|c|}{ Intestine (fish no.) } \\
\hline & & 1 & 2 & 3 & 1 & 2 & 3 \\
\hline \multirow{4}{*}{$\begin{array}{l}\text { Phage only } \\
(1 \times)\end{array}$} & 1 & 4.8 & 5.2 & 5.1 & 3.8 & 4.4 & 4.6 \\
\hline & 3 & 3.9 & 4.6 & 1.2 & 1.8 & 3.1 & 2.9 \\
\hline & 10 & $<1.0$ & 1.0 & $<1.0$ & $<1.0$ & $<1.0$ & $<1.0$ \\
\hline & 24 & $<1.0$ & $<1.0$ & $<1.0$ & $<1.0$ & $<1.0$ & $<1.0$ \\
\hline \multirow{4}{*}{$\begin{array}{l}\text { Phage + } \\
\text { L. garvieae } \\
(1 \times)\end{array}$} & 3 & 3.3 & 2.8 & 2.7 & 5.3 & 4.7 & 4.5 \\
\hline & 10 & 1.7 & $<1.0$ & 3.4 & 1.2 & 3.5 & 6.0 \\
\hline & 24 & $<1.0$ & $<1.0$ & $<1.0$ & 1.3 & 3.6 & 2.3 \\
\hline & 48 & $<1.0$ & $<1.0$ & $<1.0$ & $<1.0$ & $<1.0$ & $<1.0$ \\
\hline \multirow{3}{*}{$\begin{array}{l}\text { Phage only } \\
(3 \times)\end{array}$} & 10 & $<1.0$ & 1.2 & 2.2 & 2.3 & 2.5 & $<1.0$ \\
\hline & 24 & $<1.0$ & $<1.0$ & $<1.0$ & 1.3 & $<1.0$ & $<1.0$ \\
\hline & 48 & $<1.0$ & $<1.0$ & $<1.0$ & $<1.0$ & $<1.0$ & $<1.0$ \\
\hline
\end{tabular}

were fed with phage-impregnated dry pellets, the phage was recovered at $10^{1}$ to $10^{5} \mathrm{PFU}^{-1}$ from the stomach and intestine of fish, 1 and $3 \mathrm{~h}$ after feeding, but not after $10 \mathrm{~h}$ with 1 exception. In contrast, the phage was recovered $24 \mathrm{~h}$ after feeding, at $10^{1}$ to $10^{3}$ PFU $\mathrm{g}^{-1}$, from the intestine of fish that were fed dry pellets impregnated simultaneously with live $L$. garvieae. In the experiment in which fish were fed phage-impregnated pellets for 3 successive days, the phage was recovered from some of the intestine samples, 10 or $24 \mathrm{~h}$ after the last administration. In addition, phages were recovered at a high concentration $\left(10^{6.6}\right.$ PFU g $\left.{ }^{-1}\right)$ from fish faeces which were collected from the rearing water. Throughout the experimental period, no clinical signs of disease were observed in any of the fish examined.

\section{Protective effects of phage in Lactococcus garvieae infection}

The survival rate of yellowtail following i.p. injection with Lactococcus garvieae was much higher (90\%) in fish injected with the phage than that of control fish $(45 \%)$ without phage injection (Expt 1, Fig. 5). When fish were injected with phage at different hours after bacterial challenge, protective effects were higher in fish that received phage treatment at the earlier time; survival rates over $10 \mathrm{~d}$ were 100,80 , and $50 \%$ for groups injected 0,1 , and $24 \mathrm{~h}$ after bacterial challenge, respectively, and $10 \%$ in control fish without phage injection (Expt 2, Fig. 6a). A distinct delay in mortality was observed in all fish groups receiving phage, compared with the control. A similar protective effect was

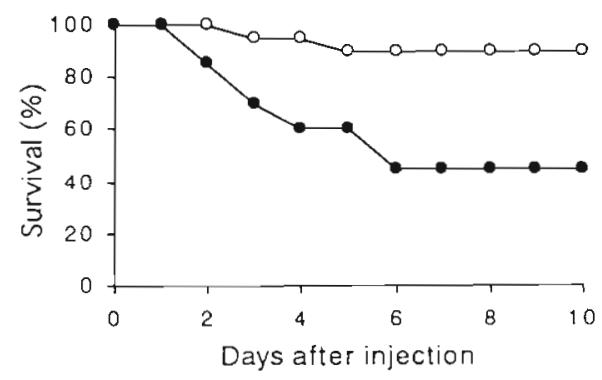

Fig. 5. Seriola quinqueradiata. Effects of administration of the phage PLgY-16 in young yellowtail challenged with Lactococcus garvieae (Expt 1). Fish $(\mathrm{N}=20)$ were intraperitoneally injected with the phage $\left(10^{75}\right.$ PFU fish $\left.{ }^{-1}\right), 1 \mathrm{~h}$ after bacterial challenge $\left(10^{8.7} \mathrm{CFU} \mathrm{fish}^{-1}\right)$. (O) Injected with phage, (0) control without phage injection
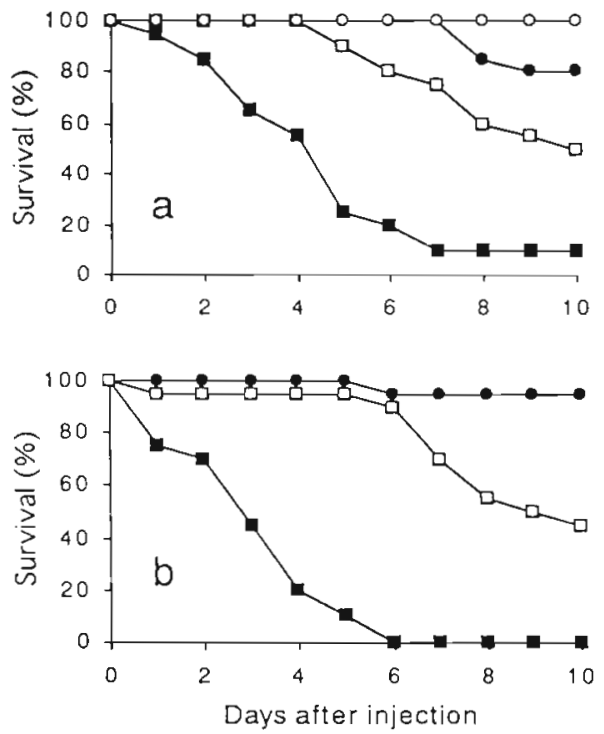

Fig. 6. Seriola quinqueradiata. Effects of administration of the phage PLgY-16 in young yellowtail challenged with Lactococcus garvieae (Expt 2). (a) Fish $(\mathrm{N}=20)$ were intraperitoneally injected with the phage $\left(10^{72} \mathrm{PFU}\right.$ fish $\left.{ }^{-1}\right), 0,1$, and $24 \mathrm{~h}$ after the bacterial challenge $\left(10^{\text {i. }} \mathrm{CFU}\right.$ fish $\left.{ }^{-1}\right)$. (b) Fish ( $\mathrm{N}=$ $20)$ received previously phage-infected bacteria as the source of phage, 1 and $24 \mathrm{~h}$ after the bacterial challenge. (0) Injected simultaneously with bacteria and phage, injected with phage $1 \mathrm{~h}$ after the bacterial challenge, (D) injected with phage $24 \mathrm{~h}$ after the bacterial challenge, ( $)$ control without phage injection

demonstrated in fish receiving $L$. garvieae cells which were previously infected in vitro with phage, as a source of phage, after bacterial challenge (Expt 2 , Fig. 6b). These mortalities of phage-treated fish were significantly lower than phage-untreated control fish, with a significance level of $\alpha=0.05$ in a chi-squared test.

Survival rates of fish fed with phage-impregnated feed and challenged $1 \mathrm{~h}$ later by anal intubation of live Lactococcus garvieae are shown in Fig. 7. Mortality in 


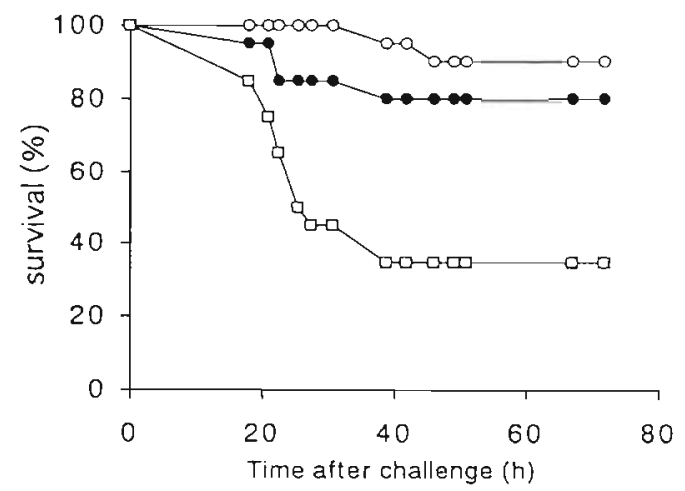

Fig. 7. Seriola quinqueradiata. Phage treatment of yellowtail infected with Lactococcus garvieae (Expt 3). Fish $(N=20$ ) received feed impregnated with the PLgY-16 phage (O), with both phage and live cells of $L$. garvieae $(\bullet)$, or with bacteria alone as the control $(\square)$ at a feeding rate of $2 \%$ body weight $1 \mathrm{~h}$ after feeding fish were challenged by anal intubation with live $L$. garvieae $\left(10^{85} \mathrm{CFU}\right.$ fish $\left.^{-1}\right)$. Concentrations of phage and L. garvieae in feed pellets were $10^{7.4} \mathrm{PFU} \mathrm{g}^{-1}$ and $10^{8.8}$ CFU g ${ }^{-1}$, respectively

the control fish, which received feed without phage, initiated at $18 \mathrm{~h}$ and terminated at $38 \mathrm{~h}$ after the challenge. The cumulative mortality at $72 \mathrm{~h}$ was $65 \%$, while the mortality was $10 \%$ in fish receiving feed impregnated with phage alone and $20 \%$ in fish given feed co-impregnated with phage and $L$. garvieae. The mortality of fish that received phage was significantly lower $(\alpha=0.05)$ than control fish fed the phage-free

Table 2. Seriola quinqueradiata. Detection of the phage PLgY-16 and Lactococcus garvieae from yellowtail (Expt 4). Fish (average $9 \mathrm{~g}$ ) were fed with phage-impregnated feed $\left(10^{7.9} \mathrm{PFU} \mathrm{g}{ }^{-1}\right)$ or with phage-free feed at a feeding rate of $2 \%$ body weight, and $1 \mathrm{~h}$ after feeding fish were challenged by anal intubation of live L. garvieae $\left(10^{85} \mathrm{CFU} \mathrm{fish}^{-1}\right)$

\begin{tabular}{|c|c|c|c|c|c|c|c|}
\hline \multirow{3}{*}{$\begin{array}{l}\text { Time } \\
\text { (h) }\end{array}$} & \multirow{3}{*}{$\begin{array}{l}\text { Fish } \\
\text { no. }\end{array}$} & \multicolumn{6}{|c|}{ Number of phage or $L$. garvieae $\left(\log _{10} \mathrm{PFU}\right.$ or CFU g $\left.{ }^{-1}\right)$} \\
\hline & & \multicolumn{3}{|c|}{ Experiment (with phage) } & \multicolumn{3}{|c|}{ Control (without phage) } \\
\hline & & $\begin{array}{l}\text { Intestine } \\
\text { (PFU) }\end{array}$ & $\begin{array}{c}\text { Spleen } \\
\text { (PFU) }\end{array}$ & $\begin{array}{l}\text { Spleen } \\
\text { (CFU) }\end{array}$ & $\begin{array}{l}\text { Intestine } \\
\quad(\mathrm{PFU})\end{array}$ & $\begin{array}{l}\text { Spleen } \\
\text { (PFU) }\end{array}$ & $\begin{array}{l}\text { Spleen } \\
\text { (CFU) }\end{array}$ \\
\hline \multirow[t]{3}{*}{3} & 1 & 5.5 & $<2.0$ & 3.7 & $<1.0$ & $<2.0$ & 4.3 \\
\hline & 2 & 4.3 & $<2.0$ & 3.8 & $<1.0$ & $<2.0$ & 2.2 \\
\hline & 3 & 2.2 & $<2.0$ & $<2.0$ & $<1.0$ & $<2.0$ & 2.4 \\
\hline \multirow[t]{3}{*}{10} & 1 & $<1.0$ & $<2.0$ & $<2.0$ & $<1.0$ & $<2.0$ & 7.6 \\
\hline & 2 & 6.1 & $>6.5$ & 6.5 & $<1.0$ & $<2.0$ & 6.7 \\
\hline & 3 & $<1.0$ & $<2.0$ & $<2.0$ & $<1.0$ & $<2.0$ & 6.1 \\
\hline \multirow[t]{3}{*}{20} & 1 & 5.7 & $>6.5$ & 6.2 & $<1.0$ & $<2.0$ & 3.0 \\
\hline & 2 & 4.2 & $<2.0$ & $<2.0$ & $<1.0$ & $<2.0$ & 5.1 \\
\hline & 3 & 4.1 & $>6.5$ & 4.6 & $<1.0$ & $<2.0$ & 5.8 \\
\hline \multirow[t]{3}{*}{48} & 1 & 1.7 & 2.2 & $<2.0$ & $<1.0$ & $<2.0$ & 3.4 \\
\hline & 2 & 4.6 & $<2.0$ & $<2.0$ & $<1.0$ & $<2.0$ & 4.7 \\
\hline & 3 & 1.7 & 2.5 & $<2.0$ & $<1.0$ & $<2.0$ & 5.6 \\
\hline \multirow[t]{3}{*}{72} & 1 & $<1.0$ & $<2.0$ & $<2.0$ & $<1.0$ & $<2.0$ & 4.7 \\
\hline & 2 & $<1.0$ & $<2.0$ & $<2.0$ & $<1.0$ & $<2.0$ & 5.7 \\
\hline & 3 & $<1.0$ & $<2.0$ & $<2.0$ & $<1.0$ & $<2.0$ & 4.9 \\
\hline
\end{tabular}

pellet. Inoculated L. garvieae were isolated from all the spleens of dead fish, the bacterial number $(\mathrm{N}=3)$ being $10^{7.4}$ to $10^{8.8} \mathrm{CFU} \mathrm{g}^{-1}$. In a separate challenge experiment using oral administration of phage and anal intubation of $L$. garvieae, phage was detected in the intestines of the phage-treated fish 3 to $48 \mathrm{~h}$ later, with a maximum $10^{6} \mathrm{PFU} \mathrm{g}^{-1}$, but not $72 \mathrm{~h}$ later (Table 2). Phages were also detected in the spleens of the phage-treated fish 10 to $48 \mathrm{~h}$ later. No PFUs were detected in any of the control fish samples. L. garvieae were isolated from the spleens of the control fish throughout the experimental period ( $72 \mathrm{~h}$ ), while they were isolated sporadically and had disappeared from the spleens of the phage-received fish after $48 \mathrm{~h}$.

\section{DISCUSSION}

The present in vitro investigation revealed that the Lactococcus garvieae phages are tolerant to physicochemical factors such as water temperatures ranging 5 to $37^{\circ} \mathrm{C}$ and salinity varying from distilled water to double-strength artificial seawater, though the survival time in untreated natural seawater was relatively short. They were also stable in fish feed and yellowtail serum. These stabilities of phages with respect to environmental factors are of practical value for phage-control. The long survival of the phages in distilled water may suggest their terrestrial origin, if the requirement of inorganic salts such as $\mathrm{NaCl}$ and $\mathrm{Mg}$ - or $\mathrm{Ca}$-salt for retention of viability is a property of marine phages as reported by Hidaka (1972). This coincides with the terrestrial origin of $L$ garvieae, which was suggested by the fact that they do not require $\mathrm{NaCl}$ for growth (Kusuda et al. 1976). Factors that could adversely influence the survival of phages were $\mathrm{pH}$ and probably digestive enzymes of alimentary tracts of yellowtail. A pH of 3.0 or lower directly decreased the infectivity of phage, and a stronger effect of such a low acidity was observed in the presence of extracts of alimentary tracts, particularly from the pyloric caecum. However, it seems that resistance to such low acidity is not a requisite for in vivo survival of phage, since the $\mathrm{pH}$ levels of stomach, intestine and pyloric caecum fluids of cultured yellowtail were reported to be $\mathrm{pH}$ 5.2 to $6.0,6.2$ to 6.4 , and 6.0 to 6.2 , respectively, when empty (Morishita et al. 1964), and $\mathrm{pH} 5.0$ to $5.4,3.4$ to 5.6 and 5.4 to 6.2 in the stomach 2,5, and $24 \mathrm{~h}$, respectively, after feeding (Ozaki 1971). A simi- 
lar effect of low acidity was reported for phages of enteropathogenic Escherichia coli: no decrease in the numbers of phages was observed at $\mathrm{pH} 3.5$ but a great decrease at $\mathrm{pH} 2.0$ and 2.5 was seen after incubation $\left(37^{\circ} \mathrm{C}, 1 \mathrm{~h}\right)$ in milk whey, and this phage-lethal effect of the acid was also demonstrated in the abomasum of calf after feeding with milk (Smith et al. 1987b).

The present study demonstrated the effectiveness of i.p. injection of the PLgY phage in treating young yellowtail i.p. injected with Lactococcus garvieae (Figs. 5 \& 6a). The results suggest that phage administration might be useful as a therapeutic measure at an early stage of systemic infection or with low burdens of bacterial infection in yellowtail. To introduce phage into the fish organs without encountering various fish defenses, phage-infected bacterial cells (as a source of phage) were injected in fish after bacterial challenge. This use of bacterial cells as a protector or vehicle did not influence the curative effect of phage (Fig. 6b). This effect is explained in part by the fact that the phage was stable in vitro in yellowtail serum and was recovered from the spleen 1 d after i.p. injection (Fig. 4). To demonstrate that the curative effect is entirely due to administered phage, Smith \& Huggins (1982) confirmed that extracts of bacteria used for propagating phage did not influence the course of the experimental Escherichia coli infection in mice. Although this was not carried out in this study, the fact that administration of L. garvieae cells as a vehicle did not enhance the protective effect suggests there was no relationship between material of bacterial origin and the protective effect.

However, parenteral administration is not a natural infection route for Lactococcus garvieae and may not be practical as a route for therapeutic administration of phage. Transmission of streptococcosis (= L. garvieae infection) in fish is horizontal, with infection occurring from direct contact with infected fish or contaminated fish feed (Kitao 1993). Taniguchi (1983) reported that experimental oral infection was successful when yellowtail were given a thawed fish feed mixed with $L$. garvieae. It was also experimentally observed that the number of adherent bacteria to yellowtail intestine is higher with a virulent substrain than with an attenuated substrain (Alim et al. 1996). These observations indicate that the oral route is the major route of transmission for $L$. garvieae in yellowtail.

The present study using juvenile yellowtail demonstrated that oral administration of phage was an effective way to protect fish from Lactococcus garvieae infection by the anal route (Fig, 7). Although coadministration of $L$. garvieae cells to fish feed did not influence the final survival rates of fish against bacterial challenge, as is the case with i.p. injection, it enhanced recovery of phage from the intestine (Table 1), suggesting that the bacterial cells played a role as protector against low $\mathrm{pH}$ and digestive enzyme barriers of stomach and/or phage progeny from infected bacterial cells recruited in the intestine. Prolonged but insufficient recovery of the phage from the intestine was observed after successive oral administration of phage. This relatively rapid clearance of phage from the intestine suggests that phage does not adhere to the intestinal tract, rather than that substance(s) present in the intestine inactivate it, because phage was detected at high levels in the faeces excreted from the body. The L. garvieae cells intubated anally were constantly detected in the spleen of control (no phage-treatment) fish, even $72 \mathrm{~h}$ after the inoculation, while the bacteria were only sporadically isolated from fish receiving phage-impregnated feed and had disappeared after $48 \mathrm{~h}$ (Table 2). On the other hand, phage was present not only in the intestine, but also in the spleen with higher PFUs and was detectable even after $48 \mathrm{~h}$. These fates of bacteria and phage indicate that the curative effect of phage was probably due to its ability to destroy $L$. garvieae cells in the spleen and/or intestine. Smith \& Huggins (1983) reported that phages protected calves, piglets, and lambs against a lethal oral infection with enteropathogenic Escherichia coli in which phage-treated animals had much lower numbers of $E$. coli in their alimentary tracts than did untreated animals, indicating destruction of the infecting bacteria by the phages.

Prior to the present study, we tried to infect juvenile yellowtail (average $5 \mathrm{~g}$ ) with Lactococcus garvieae by an oral method, in which fish were fed with bacterialoaded dry pellets $\left(10^{9} \mathrm{CFU} \mathrm{g}^{-1}\right)$, but this resulted in no mortality of test fish. The anal intubation employed in the present study was found to be a method that induced mortality in $5 \mathrm{~g}$ juvenile yellowtail. However, anal intubation as a non-parenteral challenge method may be restricted to juvenile fish with a very narrow range, because the challenge failed to cause death in larger fish. L. garvieae infection prevails even among marketable-sized yellowtail and thus we must examine the possibility of phage control in larger fish, for which it is essential to establish more reliable non-parenteral infection methods.

The present successful treatment of experimenl Lactococcus garvieae infection by oral administration of phage demonstrates the potential use of phage as both a therapeutic and prophylactic measure for naturally occurring lactococcosis of yellowtail. If phages are introduced by oral administration in the intestine of fish where virulent $L$. garvieae cells adhere or commence to multiply, it is expected that the phage will attack the pathogen. Furthermore, it will possibly be effective against bacteria invading organs other than the alimentary tract. The precise in vivo bactericidal 
mode of phage must be examined in a future study Smith \& Huggins (1982) pointed out that the reason why phages are of little value in controlling bacterial infections in man and animals is mainly their apparent low activity in vivo and rapid emergence of phageresistant bacterial mutants during treatment. As previously reported (Park et al. 1998), the PLgY-16 phage used in the present study is lytic in vitro against $75 \%$ (83 out of 111 strains) of $L$. garvieae strains including the major phage type A. As host specificity of phages is a disadvantage to their general application (Smith et al. 1987a, Barrow \& Soothill 1997), further studies should be performed for in vivo effectiveness of anti- $L$. garvieae phages having different infectivities against other virulent strains of $L$. garvieae. The latter point, appearance of phage-resistant virulent organisms, may be an important obstacle for phage control of the L. garvieae infection in cultured yellowtail. Phageresistant mutants are also fairly common in $L$. garvieae cultures, but all L. garvieae isolates from dead fish obtained during the present in vivo experiments were still susceptible to PLgY-16. In successful phage control against a generalized and a cerebral infection of mice with Escherichia coli (O18: $\left.\mathrm{K} 1: \mathrm{H} 7 \mathrm{ColV}^{+}\right)$or diarrhoea in calves by enteropathogenic $E$. coli, only the less virulent $K^{-}$type emerged as phage-resistant organisms (Smith \& Huggins 1982, 1983), but later $\mathrm{K}^{+}$ phage-resistant, virulent bacteria emerged in some of the calves treated with phages (Smith et al. 1987a). Another point which should be considered for phage control may be phage-neutralizing antibodies which were supposed to be produced against the phage administered. No such neutralizing antibodies were detected in the serum of yellowtail that repeatedly received phage-impregnated feed in the present study (data not shown).

\section{LITERATURE CITED}

Alim SR, Kawai K, Kusuda R (1996) Differences in some biological characteristics of antigenically variant Enterococcus seriolicida substrains which contribute to virulence in yellowtail, Seriola quinqueradiata. Suisanzoshoku 44: $451-456$

Aoki T, Takami K, Kitao T (1990) Drug resistance in a nonhemolytic Streptococcus sp. isolated from cultured yellowtail Seriola quinqueradiata. Dis Aquat Org 8:171-177

Barrow PA, Soothill JS (1997) Bacteriophage therapy and prophylaxis: rediscovery and renewed assessment of potential. Trend Microbiol 5:268-271

Barrow P, Lovell M, Berchieri A Jr (1998) Use of lytic bacteriophage for control of experimental Escherichia coli septıcemia and meningitis in chickens and calves. Clin Diagn Lab Immunol 5:294-298

Eldar A, Ghittino C, Asanta L, Bozzetta E, Goria M, Prearo M, Bercovier H (1996) Enterococcus seriolicida is a junior synonym of Lactococcus garvieae, a causative agent of sep- ticemia and meningoencephalitis in fish. Curr Microbiol $32: 85-88$

Hidaka T (1972) On the stability of marine bacteriophages. Bull Jpn Soc Sci Fish 38:517-523

Iida T, Wakabayashi H, Egusa S (1982) Vacrination for control of streptococcal disease in cultured yellowtail. Fish Pathol 16:201-206

Kitao T (1982) The methods for detection of Streptococcus sp., causative bacteria of streptococcal disease of cultured yellowtail (Seriola quinqueradiata)-especially, their cultural, biochemical and serological properties. Fish Pathol $17: 17-26$

Kitao T (1993) Streptococcal infections. In: Inglis V, Roberts RJ, Bromage NR (eds) Bacterial diseases of fish. Blackwell Science, Oxford, p 196-210

Kitao T, Aoki T, Iwata K (1979) Epidemiological study on streptococcicosis of cultured yellowtail (Seriola quinqueradiata). I. Distribution of Streptococcus sp. in seawater and muds around yellowtail farms. Bull Jpn Soc Sci Fish 45:567-572

Kusuda R, Kawai K, Toyoshima T, Komatsu I (1976) A new pathogenic bacterium belonging to the genus Streptococcus, isolated from an epizootic of cultured yellowtail. Bull Jpn Soc Sci Fish 42:1345-1352

Kusuda R, Kawai K, Salati F, Banner CR, Fryer JL (1991) Enterococcus seriolicida sp. nov., a fish pathogen. Int J Syst Bacteriol 41:406-409

Kusuda R, Sato H, Kawai K, Ninomiya M (1996) Increase in immunobiological activities of yellowtail immunized with formalin-killed Enterococcus seriolicida. Nippon Suisan Gakkaishi 62:780-784

Merino S, Camprubi S, Tomas JM (1990) Isolation and characterization of bacteriophage PM2 from Aeromonas hydrophila. FEMS Microbiol Lett 68:239-244

Morishita T, Noda H, Kitamikado M, Takahashi T, Tachino S (1964) On the activity of the digestive enzymes in cultured fish. J Fac Fish Pref Univ Mie 6:239-246

Muroga K (1997) Recent advances in infectious diseases of marine fish with particular reference to the case in Japan. In: Flegel TW, MacRae IH (eds) Diseases in Asian aquaculture III. Fish Health Section, Asian Fisheries Society, Manila, p 21-31

Ozaki H (1971) Digestion in stomach. In: The physiology of fishes, Vol 3. Midori Shobo, Tokyo, p 17-87

Park KH, Matsuoka S, Nakai T, Muroga K (1997) A virulent bacteriophage of Lactococcus garvieae (formerly Enterococcus seriolicida) isolated from yellowtail Seriola quinqueradiata. Dis Aquat Org 29:145-149

Park KH, Kato H, Nakai T, Muroga K (1998) Phage typing of Lactococcus garvieae (formerly Enterococcus seriolicida) a pathogen of cultured yellowtail. Fish Sci (Tokyo) 64:62-64

Paterson WD, Douglas RJ, Grinyer I, McDermott LA (1969) Isolation and preliminary characterization of some Aeromonas salmonicida bacteriophages. J Fish Res Board Can $26: 629-632$

Plumb JA (1994) Streptococcus and Enterococcus septicemia In: Health maintenance of cultured fishes. Principal microbial diseases. CRC Press, Boca Raton, FL, p 231-238

Rodgers CJ, Pringle JH, MCCarthy DH, Austin B (1981) Quantitative and qualitative studies of Aeromonas salmonicida bacteriophage. J Gen Microbiol 125:335-345

Smith HW, Huggins MB (1982) Successful treatment of experimental Escherichia cols infections in mice using phage: its general superiority over antibiotics. J Gen Microbiol 128 $307-318$

Smith HW, Huggins MB (1983) Effectiveness of phages in treating experimental Escherichia coli diarrhoea in calves, piglets and lambs. J Gen Microbiol 129:2659-26:75 
Smith HW, Huggins MB, Shaw KM (1987a) The control of experimental Escherichia coli diarrhoea in calves by means of bacteriophages. J Cen Microbiol 133:1111-1126

Smith HW, Huggins MB, Shaw KM (1987b) Factors influencing the survival and multiplication of bacteriophages in calves and in their environment. J Gen Microbiol 133: $1127-1135$

Stevenson RMW, Airdrie DW (1984) Isolation of Yersinia ruckeri bacteriophages. Appl Environ Microbiol 47: $1201-1205$

Taniguchi M (1983) Progress of streptococcicosis of yellowtail in peroral inoculation. Bull Jpn Soc Sci Fish 49:1171-1174

Teixeira LM, Merquior VLC, Vianni MCE, Carvalho MGS, Fracalanzza SEL, Steigerwalt AG, Brenner DJ, Facklam RR (1996) Phenotypic and genotypic characterization of

Editorial responsibility: David Bruno,

Aberdeen, Scotland, UK atypical Lactococcus garvieae strains isolated from water buffalos with subclinical mastitis and confirmation of $L$. garvieae as a senior subjective synonym of Enterococcus seriolicida. Int J Syst Bacteriol 46:664-668

Wu JL, Chao WJ (1982) Isolation and application of a new bacteriophage, $\phi \mathrm{ET}-1$, which infect Edwardsiella tarda, the pathogen of edwardsiellosis. CAPD Fisheries Series No. 8, Reports on Fish Disease Research (Taiwan) 4:8-17

Wu JL, Lin HM, Jan L, Hsu YL, Chang LH (1981) Biological control of fish bacterial pathogen, Aeromonas hydrophila, by bacteriophage AH1. Fish Pathol 15:271-276

Yoshida T, Endo M, Sakai M, Inglis V (1997) A cell capsule with possible involvement in resistance to opsonophagocytosis in Enterococcus seriolicida isolated from yellowtail Seriola quiqueradiata. Dis Aquat Org 29:233-235

Submitted: December 30, 1998; Accepted: March 15, 1999 Proofs received from author(s): May 28, 1999 